\title{
Pengaruh Kecerdasan Emosional terhadap Penyesuaian Diri Mahasiswa Thailand
}

\author{
M. YUSUF AHMAD* \\ SYAHRAINI TAMBAK** \\ USWATUN HASANAH***
}

\author{
*Fakultas Agama Islam (FAI) Universitas Islam Riau (UIR) Pekanbaru \\ Jl. Kaharuddin Nasution, No. 113, Perhentian Marpoyan Pekanbaru 28284. \\ ${ }^{* *}$ Fakultas Agama Islam (FAI) Universitas Islam Riau (UIR) Pekanbaru \\ Jl. Kaharuddin Nasution, No. 113, Perhentian Marpoyan Pekanbaru 28284 \\ e-mail: syahraini tambak@yahoo.co.id \\ ***Fakultas Agama Islam (FAI) Universitas Islam Riau (UIR) Pekanbaru \\ Jl. Kaharuddin Nasution, No. 113, Perhentian Marpoyan Pekanbaru 28284
}

\begin{abstract}
Individual self-adjustment is needed for survival, because humans are social beings who cannot live without others. Self-adjustment is very necessary if someone moves from one place to another. Self-adjustment greatly encourages them to improve their standard of living, not only in the fields of Education but also Economics, Social, Culture, Religion and so on. Of course, in this case, it is inseparable from problems and difficulties in communication, Thai students who study at the faculty of Islamic religion in islamic university of Riau found difficulties to adjust, because of lacking of mastering Indonesian language, communicating, lacking mingling with Indonesians, tend to be quiet many times, and also often gather with fellow Thai students, then the problem formulation in this study iswhether there is an influence of intelligence Emotional towards Thai Student Adaptation. The purpose of this study was to find out the effect of Emotional Intelligence on Thai Student Adaptation. This study is a type of correlation research that aims to find out how much influence of emotional intelligence on the self-adjustment of Thai students. Sampling used is saturated sampling method which involve the entire population to be used as a research sample because the population was less than 100 people, namely 33 students.To collect data using questionnaires and documentation, data analysis techniques using simple linear regression analysis. Based on the results of data analysis in the ANOVA table, it can be concluded that the significant value is 0.926 , which means that there is no significant influence between Emotional Intelligence and Thai Student Adaptation.
\end{abstract}

Keywords: emotional intelligence, adjustment, Thai students.

Abstrak: Penyesuaian diri individu di butuhkan untuk kelangsungan hidup, karena manusia adalah mahkluk sosial yang tidak dapat hidup tanpa orang lain. Penyesuaian diri sangat diperlukan apabila seseorang pindah dari satu tempat ketempat lain. Penyesuaian diri sangat mendorong mereka untuk menigkatkan taraf kehidupan mereka, bukan sekedar bidang Pendidikan bahkan Ekonomi, Sosial, Budaya, Agama dan lain sebagainya, Oleh karena itu sudah tentu dalam 
hal ini tidak terlepas dari permasalahan dan kesulitan dalam berkomunikasi, mahasiswa thailand yang kuliah di fakultas agama islam universitas islam riau, sulit menyesuaikan diri, karna di sebabkan kurang menguasai bahasa indonesia, berkomunikasi, kurang berbaur dengan orang indonesia, cenderung banyak diam, dan juga sering berkumpul dengan sesama mahasiswa thailand, maka Rumusan masalah pada penelitian ini adalah Apakah ada Pengaruh Kecerdasan Emosional Terhadap Penyesuaian Diri Mahasiswa Thailand.Tujuan penelitian ini adalah untuk mengetahui Pengaruh Kecerdasan Emosional Terhadap Penyesuaian Diri Mahasiswa Thailand. Penelitian Ini merupakan jenis penelitian korelasi yang bertujuan untuk mengetahui seberapa besar pengaruh kecerdasan emosional terhadap penyesuaian diri mahasiswa thailand. Pengambilan sampel menggunakan metode sampling jenuh yaitu mengambil seluruh populasi untuk dijadikan sampel penelitian karena populasi kurang dari 100 orang yaitu 33 orang mahasiswa, cara mengumpulkan data menggunakan angket dan dokumentasi, teknik analisis data menggunakan analisis regresi linear sederhana. Berdasarkan hasil analisis data pada tabel ANOVA dapat disimpulkan bahwa nilai signifikan 0,926 yang artinya tidak terdapat pengaruh yang signifikan antara Kecerdasan Emosional Terhadap Penyesuaian Diri Mahasiswa Thailand.

Kata kunci: kecerdasan emosional, penyesuaian diri, mahasiswa Thailand.

\section{PENDAHULUAN}

Penyesuaiandiridarisikapindividu dibutuhkanuntukkelangsunganhidup, karenamanusiaadalahmakhluksosial yang tidakdapathiduptanpa orang lain. Penyesuaiandirisangatdiperlukanapabil aseseorangpindahdarisatutempatketem pat lain.

\section{Manusia,}

selainmengalamiadaptasifisik, jugamengalamipenyesuaian-

penyesuaiansosial. Misalnya penyesuaian diri terhadap keinginankeinginan atau aturan-aturan yang diberlakukan dalam keluarga, penyesuaian diri terhadap rasa lapar, haus, nafsu-nafsu dan lain-lain, jika manusia tidak dapat memenuhi tuntutan-tuntutan atau menyesuaikan diri dengan hal-hal yang dicontohkan tersebut, dirinya akan merasa tidak enak atau tidak nyaman( Purwa Atmaja, 2011 : 356).

Penyesuaiandirisetiap orang berbeda-beda.Ada yang dapatmenyesuaikandiridengancepatdan adajuga yang menyesuaikandiridenganlambat.Seperti halnyamahasiswa patani Thailand yang datangke Indonesia khususnya provinsi
Riau, untukmenuntutIlmu di Universitas Islam Riau. Menurut pergaulanpergaulan dikampus Universitas Islam Riau, mereka cenderung susah dalam berkomunikasiserta lambat dalammenyesuaikandiridenganlingkung anbarumerekadikarenakanbahasa yang berbeda dan juga Mahasiswa patani Thailand cenderungberkumpulbersamasamadenganmereka yang samadari Patani Selatan Thailand.

Menurut A. Bangnara, (1977:1) di kutip dalam skiripsi IsmaaelTohwae-aryi dengan judul Problematika Yang Dihadapai Mahasiswa Islam Patani Dalam Melanjudkan Studi Pada Fakultas Agama Islam Universitas Islam Riau Di Provinsi Riau. Pataniadalahnamasuatutempatataudaer ah yang dikenal orang sejakdahuluadalah "PATANI DARUSSALAM".

PatanibukanhanyasekedarsalahsatuPro vinsi, bahkanmerupakannamasebuah Negara yang pernahberdaulatdanterdiridariempatPr ovinsiyaitu, Pattani, Narathiwat, Yala, Setul, dan lima kabupatendariSongklayaitu, Tipa, Natawi, Chenok, Sebayoi, Sedau, 
terletakantaraperbatasandenganlautanC ina Selatan di sebelahTimur, SelatMalaka di sebelah Barat, Thailand di sebelah Utara dan Malaysia di sebelah Selatan.

Penyesuain diri itu sendiri ada hubungan dengan bagaimana seseorang dapat menyesuaikan dirinya di lingkungannya dan mendorong mereka untuk lebih berusaha, terutama untuk meningkatkan pendidikan mereka dalam rangka memperbaiki dan membina nasib bangsa itu sendiri. Islam jugamemandangbahwapendidikanadala hhakbagisetiap orang lakilakiatauperempuan, danberlangsung.

$$
\text { Penyesuaian diri sangat }
$$

mendorong mereka untuk meningkatkan taraf kehidupan mereka, bukan sekedar bidang Pendidikan bahkan Ekonomi, Sosial, Budaya, Agama dan lain sebagainya. Oleh karena itu sudah tentu dalam hal ini tidak terlepas dari permasalahan dan kesulitan dalam berkomunikasi yang meraka hadapi termasuk dalam mengikuti perkuliyahan dan penyelesaian studi.

Untuk dapat melanjutkan studi, mahasiswa Patani Selatan Thailand banyak menghadapi permasalahan dan kesulitan-kesulitan antara lain, mahasiswa Patani Selatan Thailand yang berada di Indonesia khususnya Riau, sulit untuk menyesuaikan diri karena kesulitan menggunakan Bahasa yang berbeda antara Bahasa Indonesia dan Bahasa Patani Selatan Thailand. Walaupun mahasiswa Patani Selatan Thailand menggunakan Bahasa Melayu tetapi tidak semua dari mahasiswa Indonesia yang bisa menggunakan Bahasa Melayu, karena bahasa yang mereka pakai bukanlah bahasa melayu Riau maupun bahasa indonesia.

Dalam pembelajaran di kampus mahasiswa Patani Selatan Thailand cenderung banyak diam dikarenakan kurang mengerti dengan apa yang disampaikan oleh dosen. sedangkan dalam pergaulan mereka cenderung bergaul dan berkumpul bersama, disamping itu mahasiswa Patani kurang bisa bersosialisasi dan beradaptasi dengan mahasiswa Indonesia dalam menggunakan bahasa, sehingga terkesan lebih banyak diam.

Kecerdasanemosional

sangatpenting dimiliki seseorang karena dengan

kecerdasanemosionalsangatberpengaru hterhadapkesuksesandankebahagiaanhi dup manusia.Kecerdasanemosional (EQ) dapat membantuk dan menciptakanhubungan yang lebihkuat, seperti

suksesditempatkerjamaupundalamkehi dupanpribadi terutama dalam kehidupan sehari-hari.

Dengankecerdasanemosional yang dimiliki,

diharapkandapatmenyesuaikandirideng anmudah. Kecerdasan emosional juga dapat mematangkan pola perilaku dalam menyesuaikan diri, agar mahasiswa tidak memiliki rasa rendah diri, tidak percaya diri dan akhirnya mengakibatkan turunnya keinginan menuntut ilmu dan berkurangnya semangat dan keinginan belajar. Sejalan dengan permasalahan diatas nabi Muhammad SAW, bersabda:

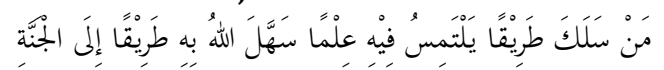

\section{Artinya : "Barang siapa yang menempuh jalan untuk mencari suatu ilmu. Niscaya Allah memudahkannya kejalan menuju surga". (HR. Turmudzi)}

Berdasarkan latar belakang di atas, penulis tertarik untuk melakukan penelitian dengan judul :"PENGARUH KECERDASAN EMOSIONAL TERHADAP PENYESUAIAN DIRI MAHASISWA THAILAND" 
Mengingat permasalahan yang disampaikan di atas, maka agar lebih fokus peneliti membatasi pada PengaruhKecerdasanEmosional Mahasiswa Thiland Fakultas Agama Islam Terhadap Penyesuaian Diri Tahun 2018.

Berdasarkan pada latar belakang masalah, maka rumusan masalah adalah Apakah ada Pengaruh Kecerdasan Emosional Terhadap Penyesuaian Diri Mahasiswa Thailand?

Berdasarkanlatarbelakang di atas, tujuanpenelitianadalah

untukmengetahuiPengaruhKecerdasanE mosional Terhadap Penyesuaian Diri Mahasiswa Thailand.

Manfaatpenelitianiniadalahsebagai berikut : (1) BagiMahasiswa Patani Selatan Thailand dapat lebih memahami kecerdasanemosionaldanpenyesuaiandi ri, sehinggadapatdiharapkan mampu menyesuaikan diri terutama di Fakultas Agama Islam Khususnya di Prodi Pendidikan Agama Islam Universitas Islam Riau; dan (2) Bagi Fakultas Agama Islam, diharapkandapatdijadikan informasi untuk melakukan pembinaan.

\section{LANDASAN TEORI Kecerdasan Emostional}

Sebelum membahas lebih jauh apa itu kecerdasan emosional maka perlu diketahui apa itu kecerdasan, kecerdasan adalah kemampuan mental umum untuk belajar dan menerapkan pengetahuan dalam memanipulasi lingkungan serta kemampuan untuk berfikir absrak(Bainbridge, 2010).

Menurut Wowo Sunaryo Kuswana (2014:214) emosi adalah suatu keadaan mental timbul secara spontan melalui usaha sadar dan sering disertai dengan perubahan fisiologis, perasaan, kegembiraan, kesedihan, hormat, benci, dan cinta.

Menurut Sunarto (2008:150) Emosi adalah pengalaman efektif yang disertai penyesuain diri individu tentang keadaan mental dan fisik dan berwujud suatu tingkah laku yang tampak.

Menurut Rohmalina Wahab (2015:159) jenis emosi manusia dibedakan dalam dua bagian, antara lain: (a) Emosi positif (emosi yang tidak menyenangkan), yaitu emosi yang menimbulkan perasaan positif pada orang yang mengalaminya, di antaranya adalah cinta, sayang, senang, gembira, kagum, dan sebagainya; dan (b) Emosi negative (emosi yang tidak menyenangkan), yaitu emosi yang menimbulkan perasaan negative pada orang yang mengalaminya, di antaranya adalah sedih, marah, benci, takut, dan sebagainya.

Menurut Kadim Masaong (2014:75) Kecerdasan emosional merupakan kemampuan merasakan, memahami, dan secara efektif menerapkan daya dan kepekaan emosi sebagai sumber energi, informasi, koneksi, dan pengaruh manusiawi.

Menurut Golmen dalam buku Suhardi Syam(2015:99) Kecerdasan emosional merujuk pada kepada kemampuan mengenali perasaan kita sendiri dan perasaan orang lain, kemampuan memotivasi diri sendiri, dan kemampuan mengelola emosi dengan baik pada diri sendiri dan dalam hubungan dengan orang lain.

\section{Konsep Penyesuaian Diri}

Penyesuain diri diartikan sebagai penguasa,yaitu memiliki kemampuan untuk membuat rencana dan mengorganisasikan respon-respon sedemikian rupa,sehingga bisa mengatasi segala macam konflik, kesulitan,dan frutasi-frutasi secara efisien.

Pada mulanya penyesuaian diri merupakan suatu konstruk psikologi yang luas dan kompleks,serta melibatkan semua reaksi individu terhadap tuntutan baik dari lingkungan 
luar maupun dari dalam diri individu itu sendiri (Desmita, 2009, hal 191).

$$
\text { Menurut Nur ghufron }
$$

(2016:52) penyesuaian diri adalah kemampuan individu dalam menghadapi tuntutan-tuntutan.Baik dari dalam diri maupun dari lingkungan sehingga terdapat keseimbangan antara pemenuhan kebutuhan dengan tuntutan lingkungan. Kemudian, tercipta keselarasaan antara individu dengan realitas.

Menurut Mohammad Asrori(2004:175) penyesuaian diri adalah sebagai suatu proses yang mencakup respons-respons mental dan behavioral yang diperjuangkan oleh individu agar dapat berhasil menghadapi kebutuhan-kebutuhan internal, ketegangan, frustasi serta untuk menghasilkan kualitas keselarasaan antara tuntutan dari dalam individu dengan tuntutan dunia atau lingkungan tempat individu berada.

Sudut pandang berikutnya adalah bahwa penyesuaian diri di maknai sebagai usaha penguasaan (mastry), yaitu kemampuan untuk merencanakan dan mengorganisasikan respons dalam cara-cara tertentu sehingga konflikkonflik, kesulitan dan frustasi tidak terjadi (Mohammad Ali 2004:175).

Dari definisi di atas dapat ditarik kesimpulkan bahwa dalam menjabarkan penyesuaian diri, manusia tidak dilahirkan dalam keadaan telah mampu menyesuaikan diri, maka penyesuaian diri terhadap lingkungan hidup, pertumbuhan dan perkembangan memerlukan proses yang cukup unik. Serta individu dalam menghadapi tuntutan-tuntutan baik dari dalam diri maupun dari luar harus mampu untuk keseimbangan antara pemenuhan kebutuhan dengan tuntutan lingkungan, kemudian memahami dengan baik serta misalnya dalam lingkungan yaitu mampu berinteraksi, berbahasa, beradaptasi, dengan social dan mampu menyesuaikannya sehingga kita dapat memahami diri kita, lingkungan, serta orang yang dekat dengan kita dan individu dapat mengatasi kebutuhan dari dalam diri, ketegangan, frustasi, dan konflik, dan keharmonisan atas tuntutan dalam dunia sekitar.

Terdapat beberapa penelitian yang mengangkat tentang materi Emosional Inteligensi di berbagai perguruan tinggi.Dari beberapa penelitian tersebut terdapat berbagai macam fokus yang ingin dianalisis, baik mengenai peranannya, hubungannya, dan urgensi emosional inteligence. Dari beberapa penelitian tentang emosional dapat disebutkan sebagai berikut :

Pertama, penelitian yang ditulis oleh Jurnita, dengan judul : hubungan kecerdasan emosional dengan Akhlak terpuji siswa Madrasah Aliyah Swasta (MAS) Masmur Pekanbaru di FAI UIR 2013. Dengan hubungan kecerdasan emosional maka tingkat kecerdasan emosional mereka meningkat, yakni munculnya rasa cinta kepada sang khalik, menjujung tinggi nilai-nilai agama, memiliki komitmen yang kuat dalam meraih cita-cita maupun komitmen dalam mengamalkan nilainilai-nilai ajaran islam. Disamping itu timbul kesadaran untuk tidak terpengaruh terhadap model pergaulan yang negatif.

Kedua, penelitian yang ditulis oleh Gatot NurluqmanUniversitas Islam Negeri (UIN) Maulana Malik Ibrahim Malang yang berjudul "urgensi kecerdasan emosional sebagai paradigma Baru Pendidikan Anak Di Lingkungan Keluarga" pada tahun 1997, penelitian yang menggunakan pendekatan kuantitatif ini memaparkan tentang pentingnya mengembangkan dan menjadikan paradiqma emosional intelegensi sebagai konsep yang harus mendapat perhatian untuk 
dikembangkan dalam lingkungan pendidikan formal maupun non formal, namun penelitian ini juga tidak memisah antara urgensi aspek-aspek kecerdasan yang lain termasuk didalamnya kecerdasan spiritual dengan memberikan nilai yang berlebihan terhadap aspek kecerdasan emosional sebagai paradiqma yang begitu penting dalam usaha mendidik dan memebesarkan anak.

Ketiga, penelitian selanjutnya berjudul "Hubungan antara kecerdasan emosional dengan prestasi belajar pada siswa kelas II SMU Lab School Jakarta Timur."Skiripsi ini ditulis oleh Amalia Sawitri WahyunimgsihUniversitas Persada Indonesia Y.A.I Jakarta.Dalam penelitian ini menggunakan pendekatan kuantitatif dengan prestasi belajar siswa tahun 2004 .Analisis datanya dengan menggunakan produc Momen dan nialai koefisien realibilitasnya menggunakan rumus Alpha Cronbach.

Keempat, penelitian dengan judul "peranan kecerdasan emosional dalam meningkatkan Kualitas Belajar Pendidikan Agama Islam siswa AMK Kosgoro I Lawang Malaang" yang ditulis oleh Andik Bambang Universitas Islam Negeri (UIN) Maulana Malik Ibrahim
Malang tahun 2004.Penelitian yang menggunakan pendekatan kualitatif ini dilatar belakangi oleh pendapat para ahli yang mengatakan bahwa IQ hanya mempunyai peran sekitar $20 \%$ dalam menentukan keberhasilan hidup. Sedangkan $80 \%$ sisanya ditentukan oleh faktor-faktor lain.

Dari beberapa penelitian di atas, ada yang memiliki persamaan judul maupun bahasan yang akan dibahas dalam skiripsi yang peneliti tulis.Namun persamaan itu hanya terdapat pada satu segi saja yakni pada emosional Inteligensi.Sehingga dapat disimpulkan bahwa belum ada satu skiripsi pun yang membahas tentang Pengaruh Kecerdasan Emosional Terhadap Penyesuaian Diri Mahasiswa Thailand di Pendidikan Agama Islam Fakultas Agama Islam Universitas Islam Riau.

\section{Konsep Operasional}

Konsep Operasional adalah konsep yang digunakan untuk menjabarkan atau memberi batasan terhadap konsep teoritis. Adapun Komponen kecerdasan emosional menurut Syam (2015:99) dengan indikator sebagai berikut :

Tabel 1

Konsep Operasional

\begin{tabular}{lll}
\hline \multicolumn{1}{c}{ Variabel } & Aspek & \multicolumn{1}{c}{ Indikator } \\
\hline Kecerdasan & a. Mengenali emosi & 1. Kesadaran emosi \\
Emosional & & 2. Penilaian diri \\
$($ Variabel X) & & 3. Percaya diri \\
& & 4. Peka terhadap perasaan \\
\cline { 2 - 3 } & b. Mengelola emosi & 1. Mengenali dan kendali \\
& & 2. Dapat dipercaya \\
& & 3. Kewaspadaan \\
& & 1. Dorongan berprestasi \\
& c. Memotivasi diri & 2. Inisiatif \\
& sendiri & 3. Komitmen \\
& & 4. Optimism \\
\hline
\end{tabular}




\begin{tabular}{|c|c|c|}
\hline & $\begin{array}{l}\text { d. } \begin{array}{l}\text { Mengenali } \\
\text { orang lain }\end{array}\end{array}$ & $\begin{array}{l}\text { 1. Memahami orang } \\
\text { lain } \\
\text { 2. Mengembangkan orang lain } \\
\text { 3. Mengatasi keragaman } \\
\text { 4. Orientasi pelayanan }\end{array}$ \\
\hline & e. Membina Hubungan & $\begin{array}{ll}\text { 1. } & \text { Komunikasi } \\
\text { 2. } & \text { Kepemimpinan } \\
\text { 3. } & \text { Manajemen konflik } \\
& \text { Pengikat jaringan } \\
\end{array}$ \\
\hline \multirow[t]{3}{*}{$\begin{array}{l}\text { Penyesuaian } \\
\text { (Variabel Y) }\end{array}$} & $\begin{array}{ll}\text { a. } & \text { Penyesuaian diri } \\
\text { personal }\end{array}$ & $\begin{array}{ll}\text { 1. } & \text { Kesehatan Fisik } \\
\text { 2. } & \text { Kematangan emosi dan } \\
\text { control emosi } \\
\text { 3. Frustasi } \\
\text { 4. Perasaan salah } \\
\text { Moral dan religious }\end{array}$ \\
\hline & $\begin{array}{l}\text { b. Penyesuaian diri } \\
\text { social }\end{array}$ & $\begin{array}{l}\text { 1. Rumah dan keluarga } \\
\text { 2. Tanggung jawab berupa } \\
\text { pembatasan dan larangan. } \\
\text { 3. Lingkungan sekolah } \\
\text { Masyarakat }\end{array}$ \\
\hline & $\begin{array}{llr}\text { c. } & \begin{array}{l}\text { Penyesuaian } \\
\text { material } \\
\text { perkawinan }\end{array} & \text { atau } \\
& \end{array}$ & $\begin{array}{l}\text { 1. Terjadinya hubungan yang } \\
\text { baik } \\
\text { 2. Kehidupan yang efektif } \\
\text { 3. Bermanfaat } \\
\text { Tanggung jawab }\end{array}$ \\
\hline
\end{tabular}

Sumber: Buku psikologi perkembangan peserta didik, Suhardi Syam (2015:99)

Buku teori teori psikologi, Nur Ghufron (2016:52)

Adapun hipotesis pada penelitian ini yaitu:

Ha : Terdapat Pengaruh secara signifikansi antara kecerdasan emosional terhadap penyesuaian diri mahasiswa Thailand Fakultas Agama Islam Universitas Islam Riau

HO : Tidak Terdapat Pengaruh secara signifikansi antara kecerdasan emosional terhadap penyesuaian diri mahasiswa Thailand Fakultas Agama Islam Universitas Islam Riau

\section{METODE}

Penelitianinimerupakanpenelitian korelasikarenapenelitianinibermaksudu ntukmengetahuipengaruhantaradua variable, yakniKecerdasanEmosional (X) sebagaivariablebebasdanPenyesuaiandi ri (Y) Sebagaivariableterikat.

Penelitianinidilakukan di Fakultas Agama Islam Universitas Islam Riau JL.KaharuddinNasution

NO.113,SimpangTiga, Bukit Raya, Kota Pekanbaru, Riau 28284.Penelitianini di rencanakanselamaempatbulan, terhitungdaribulan November 2017 hingga Februari 2018.

SubjekpenelitianiniadalahMahasis wa Patani Selatan Thailand di Fakultas Agama Islam Universitas Islam Riau Pekanbaru, sedangkanobjekpenelitianadalahPengar uhKecerdasanEmosionalTerhadapPenye suaianDiriMahasiswa Thailand di 
Pendidikan Agama Islam FakultasAgam Islam Universitas Islam Riau Pekanbaru. Populasipenelitianini adalah seluruh Mahasiswa Patani Selatan Thailand yang belajar diFakultas Agama Islam, berjumlah 33 orang sedangkan sampel adalah seluruh populasi.

Dalam teknik pengumpulan data penulismenggunakan angket dan dokumentasi,

Angketadalahmengajukanbeberapapert anyaankepadaresponden, yakni mahasiswa Patani Selatan Thailand, tentangmasalah yang berkaitandenganpenelitian yang penulis lakukan sedangkan Dokumentasi adalah data-data apa saja yang diperlukan untuk pengumpulan data.

Pengolahan data dilakukansetelahsemua data terkumpuldantelahmendapatgambaran menyeluruhtentangobjekpenelitian, makaselanjutnyadilakukanpengolahan data (SuharsimiArikunto, 2006:133).

Sebelum penelitian dilaksanakan maka langkah yang utama adalah melaksanakan uji coba intrumen penelitian, uji coba dari butir-butir intrumen pada kedua variabel dimasukkan untuk menguji keabsahan dan kehandalan butir-butir intrumen yang digunakana dalam penelitian, untuk itu uji coba harus di uji validitasnya dan realibilitasnya.

Dalam penelitian ini validitas instrumen diuji dengan menggunakan bantuan program SPPS 20 dengan metode korelasi produc moment. Teknik uji validitas instruem dengan korelasi produc moment yaitu dengan cara mengkorelasi skor tiap item dengan skor yang merupakan jumlah tiap skor item.

Uji normalitas ini berguna untuk menentukan apakah ada yang telah dikumpulkan berdistribusi normal atau tidak. Normalitas data merupakan syarat pokok yang harus dipenuhi dalan analisis parametric. Normalitas data merupakan hal penting karena dengan data yang terdistribusi normal, maka data tersebut dianggab dapat mewakili populasi.

Deteksi normalitas dilakukan dengan melihat grafik Normal Pribability Plot. Untuk menguji apakah distribusi data normal probability plot yang membandingkan distribusi kumulatif dari data sesungguhnya dengan distribusi kumulatif dari distribusi normal. Jika data menyebar disekitar garis dan mengikuti arah garis diagonal maka model regresi memenuhi asumsi normalitas tetapi jika dta menyebar jauh dari garis diagonal dan atau mengikuti garis diagonal maka model regresi tidak memenuhi asumsi normalitas, hasil pengujian normalitas (Hartono,2004: 36-39)

\section{HASIL}

Sebelum berubah nama menjadi Fakultas Agama Islam (PAI), Fakultas Ini bernama Fakultas Ushuluddin. Fakultas ini adalah merupakan fakultas tertua dilingkungan Universitas Islam Riau (UIR). Fakultas ini berdiri pada tanggal 17 mei 1963. Sejak tahun 1969 fakultas ini telah diakui untuk program sarjana muda lengkap jurusan dakwah.Pada tahun 1967/1988 mulai dibuka program sarjana lengkap dengan menerapkan Sistem Kredit Semester (SKS).

Pada tahun 1991 status Fakultas Ushuluddin meningkat menjadi status disamakan sesuai dengan SK Menteri Agama Nomor 257/1991 tanggal 17 Oktober 1991. Fakultas Ushuluddin yang mengasuh jurusan dakwah menjadi jurusan dakwah menjadi jurusan tersendiri dilingkungan Perguruan Tinggi Agama Islam dengan dikeluarkan SK Menteri Agama Nomor: E/189/1996 tanggal 12 November 1996, sekaligus menyebabkan perubahan dan Fakultas Ushuluddin 
menjadi Fakultas Agama Islam, dan jadilah Fakultas Agama Islam mengasuh dua jurusan yaitu, jurusan Akidah Filsafat Islam dengan status disamakan dan jurusan yaitu Komunikasi Penyiar Islam (Dakwah) berstatus terdaftar. Dengan perubahan nama Fakultas tersebut sangat memberi peluang untuk membuka jurusan baru.

Maka pada tahun 2000/2001 Fakultas Agama Islam membuka jurusan baru dengan klasifikasi sebagai berikut: (a) Jurusan Ekonomi Islam ( Syari'ah) S1; (b) Jurusan Pendidikan Agama Islam (PAI) S1; (c) Jurusan Pendidkan Islam Anak Usia Dini (PIAUD); (d) Jurusan Perbankan Syariah; (e) Jurusan Pendidikan Bahasa Arab; (f) Pendidkan Guru Kelas Madrasah Ibtidayyah (PGKMI) D2; dan (g) Pendidikan Guru Taman Kanak-Kanak (PGTKI) D2

Dari Tujuh jurusan diatas bahwa yang masih aktif pada saat sekarang ini adalah Lima jurusan yaitu Jurusan Pendidkan Agama Islam (PAI) S1, Jurusan Ekonomi Islam (Syariah) S1, Jurusan Pendidikan Islam Anak Usia Dini (PIAUD), Perbankan Syariah, dan Pendidikan Bahasa Arab.

Adapun visi Fakultas Agama Islam adalah: "Pusat Keunggulan Studi IlmuIlmu Keislaman dan Pengembangan Sumber Daya Manusia di Provinsi Riau Tahun 2020."

Sedangkan misi Fakultas Agama Islam adalah: (a) Menyelenggarakan pendidikan dan pengajaran yang berkualitas dan unggul dalam ilmu-ilmu keislaman dengan metode modern; (b) Melakukan penelitian dan pengabdian yang berkualitas secara berkesinambungan dalam rangka pengembangan ilmu-ilmukeislaman dan mempublikasikanya baik nasional, regional maupun internasional; (c) Mengembangkan manajeman Fakultas Agama Islam dalam memberikan pelayanan optimal sesuai dengan tuntunan kompetisi global serta menyediakan sarana prasarana pendidikan berteknologi modern; (d) Menjalin kerjasama dengan lembaga dan instansi terkait, baik dalam maupun luar negeri untuk kepentingan pengembangan dakwah dan masyarakat Islam; dan (e) Membina nilai-nilai spiritual, moral dan etika dan membangun kreativitas, etos kerja dan life skills sivitas akademika yang berlandaskan akhlakul kharimah serta membangun jejaring alumni.

TujuanFakultas Agama Islam adalah: (a) Menghasilkan lulusan yang berkualitas, memiliki kompetensi, berjiwa enterpreneur, dan berdaya saing tinggi baik ditingkat lokal, nasional maupun internasional; (b) Menghasilkan penelitian dan pengabdian yang berkualitas dan bermanfaat bagi pengembangan IPTEK dan mengarah pada publikasi nasional dan internasional; (c) Mewujudkan manajemen Fakultas Agama Islam yang baik dengan memberikan pelayanan optimal sesuai dengan tuntunan kompetensiglobal serta menyediakan sarana prasarana pendidikan teknologi modern; (d) Menghasilkan kerjasama dengan lembaga pendidikan dan dunia usaha baik pemerintah maupun swasta ditingkat lokal, nasional maupun intrernasional; dan (e) Mewujudkan pembinaan nilai-nilai spiritual, moral dan etika, dan terlaksananya budaya akademik yang kreatif, inovatif, etos kerja, life skills agar terwujud mahasiswa yang berprestasi dan tauladan ditengah masyarakat serta menjalin silahturahmi secara intensif dengan alumni untuk membangun kejayaan dan kelanggengan Fakultas.

Penelitian ini bertujuan untuk mengetahui pengaruh kecerdasan emosional terhadap penyesuaian diri mahasiswa Thailand Fakultas Agama Islam.Populasi penelitian ini adalah 
seluruh mahasiswa Thailand dari semester 2 sampai semester 8 yang berjumlah 33 orang.

Responden diminta mengisi indentitas diri sebelum menjawab pernyataan yang di ajukan dan menchecklis $(\sqrt{ })$ bebas setiap pernyataan yang berjumlah 19 penyataan, yang terdiri dari Variabel $\mathrm{X}$ yaituKecerdasan Emosional sebanyak 9 pernyataandan Variabel $Y$ yaitu Penyesuaian Diri berjumlah 10 pernyataan.

Yang mana variabel $\mathrm{x}$ akan berpengaruh pada variabel y. Berikut ini hasil dari penyebaran angket yang berjumlah 19 pernyataan dan juga deskripsi karakteristik responden berdasarkan jenis kelamin, jurusan dan Semester yang berjumlah 33 orang.

\section{Pengelolaan Data}

Data yang akan disajikan pada penelitian ini adalah data yang dikumpulkan dari lapangan. Adapun teknik pengumpulan data yang digunakan adalah angket.Hasil angket yang telah diperoleh diharapkan mampu menunjukkan apakah terdapat pengaruh kecerdasan emosional terhadap penyesuaian diri mahasiswa Thailand Fakultas Agama Islam Universitas Islam Riau.

Angket ini diberikan kepada 33 responden yang menjadi sampel dalam penelitian ini.Dalam angket tersebut diberikan 4 (empat) alternatif jawaban (sangat setuju, setuju, kurang setuju, sangat tidak setuju) yang dapat dipilih oleh responden sesuai pernyataan yang diajukan. Kemudian data akan diolah menggunakan aplikasi IBM SPSS Statistics 20.

\section{Analisis Data Uji Validitas Dan Uji Releabilitas}

Uji validitas dilakukan dengan dengan metode korelasi Pearson dengan mengkorelasikan skor item dengan skor total item.Untuk menentukan kevalidan kuesioner pada angket dapat dilihat dilakukan dengan melihat nilai signifikan yang terdapat pada tabel. Hasil penelitian dapat dilihat pada tabel berikut:

Tabel 2

Uji Validitas Variabel Kecerdasan Emosional

\begin{tabular}{llll}
\hline Pernyataan & Nilai Sig & Nilai $\mathbf{r}$ & Keterangan \\
\hline P1 &, 397 &, 022 & Valid \\
\hline P2 &,- 327 &, 064 & Tidak Valid \\
\hline P3 &, 254 &, 154 & Tidak Valid \\
\hline P4 &, 215 &, 230 & Tidak Valid \\
\hline P5 &,- 484 &, 004 & Valid \\
\hline P6 &, 130 &, 470 & Tidak Valid \\
\hline P7 &, 451 &, 009 & Valid \\
\hline P8 &, 312 &, 077 & Tidak Valid \\
\hline P9 &,- 247 &, 165 & Tidak Valid \\
\hline P10 &, 574 &, 000 & Valid \\
\hline P11 &, 282 &, 112 & Tidak Valid \\
\hline P12 &, 081 &, 655 & Tidak Valid \\
\hline P13 &, 420 &, 015 & Valid \\
\hline
\end{tabular}




\begin{tabular}{llll} 
P14 &, 672 &, 000 & Valid \\
\hline P15 &,- 068 &, 707 & Tidak Valid \\
\hline P16 &, 301 &, 088 & TidakValid \\
\hline P17 &, 039 &, 828 & Tidak Valid \\
\hline P18 &, 804 &, 000 & Valid \\
\hline P19 &, 458 &, 007 & Valid \\
\hline P20 &, 737 &, 000 & Valid \\
\hline
\end{tabular}

Item dikatakan valid jika nilai probabilitas atau signifikansi $<0,05$, tetapi jika signifikansi $>0,05$ maka item tidak valid. Berdasarkan tabel di atas dari 20 pertanyaan yang dinyatakan valid hanya 9 pertanyaan, karena nilai probabilitas atau signifikansi dari 11 pertanyaan $>0,05$. Hasil diperoleh melalui aplikasi IBM SPSS Statistics 20.
Kemudian item instrumen yang dinyatakan valid diuji kembali dengan menggunakan IBM SPSS Statistics 20 untuk mengetahui tingkat reliablititasnya, dimana item yang masuk pengujian hanya yang valid saja. Adapun hasil uji instrumen tersebut sebagai berikut:

\section{Tabel 3}

Hasil Uji Reliabilitas Variabel KecerdasanEmosional (XReliability Statistics

\begin{tabular}{ll}
\hline Cronbach's Alpha & N of Items \\
\hline, 582 & 9 \\
\hline
\end{tabular}

Berdasarkan tabel 14 di atas, dapat diketahui bahwa seluruh instrumen dinyatakan tidak reliabel. Sesuai dengan teori yang telah dijelaskan pada bab III, sebuah instrumen dinyatakan reliabel jika hasil
Cronbach's Alpha menunjukkan angka minimal 0,6 dan nilai Crinbach's Alpha pada tabel di atas adalah 0,582 . Hal ini menunjukkan bahwa 0,582 < 0,6 sehingga instrumen yang telah di uji di nyatakan tidak reliabel.

Tabel 4

Uji Validitas Variabel Penyesuaian Diri

\begin{tabular}{llll}
\hline Pernyataan & Nilai Sig & Nilai $\mathbf{~}$ & Keterangan \\
\hline P1 &, 226 &, 207 & Tidak Valid \\
\hline P2 &, 243 &, 173 & Tidak Valid \\
\hline P3 &, 329 &, 062 & Tidak Valid \\
\hline P4 &, 372 &, 033 & Valid \\
\hline P5 &, 576 &, 000 & Valid \\
\hline P6 &, 490 &, 004 & Valid \\
\hline P7 &, 426 &, 013 & Valid \\
\hline P8 &, 327 &, 064 & Tidak Valid \\
\hline P9 &, 535 &, 001 & Tidak Valid \\
\hline
\end{tabular}




\begin{tabular}{llll} 
P10 &, 182 &, 310 & Valid \\
\hline P11 &, 741 &, 000 & Valid \\
\hline P12 &, 428 &, 013 & Valid \\
\hline P13 &, 396 &, 023 & Valid \\
\hline P14 &, 438 &, 011 & Valid \\
\hline P15 &, 496 &, 003 & Valid \\
\hline
\end{tabular}

Item dikatakan valid jika nilai probabilitas atau signifikansi $<0,05$, tetapi jika signifikansi > 0,05 maka item tidak valid. Berdasarkan tabel di atas dari 15 pertanyaan yang dinyatakan valid hanya 10 pertanyaan, karena nilai probabilitas atau signifikansi dari 5 pertanyaan > 0,05. Hasil diperoleh melalui aplikasi IBM SPSS Statistics 20.
Kemudian item instrumen yang dinyatakan valid diuji kembali dengan menggunakan IBM SPSS Statistics 20 untuk mengetahui tingkat reliablititasnya, dimana item yang masuk pengujian hanya yang valid saja. Adapun hasil uji instrumen tersebut sebagai berikut:

Tabel 5

Hasil Uji Reliabilitas Variabel Penyesuaian Diri (Y)

\begin{tabular}{ll}
\hline Cronbach's Alpha & N of Items \\
\hline, 696 & 10 \\
\hline
\end{tabular}

Berdasarkan tabel 16 di atas, dapat diketahui bahwa seluruh instrumen dinyatakan reliabel. Sesuai dengan teori yang telah dijelaskan pada bab III, sebuah instrumen dinyatakan reliabel jika hasil Cronbach's Alpha menunjukkan angka minimal 0,6 dan nilai Crinbach's Alpha pada tabel di atas adalah 0,696. Hal ini menunjukkan bahwa 0,696>0,6 sehingga instrumen yang telah di uji di nyatakan reliabel dan dapat digunakan sebagai instrumen penelitian.

\section{Analisis Regresi Linear Sederhana}

Angket yang telah diperoleh kemudian diolah, dianalisis, dan disimpulkan menggunakan regreasi linier sederhana digunakan untuk mengetahui pengaruh Kecerdasan Emosional terhadap Penyesuain Diri Mahasiswa Thailand di Fakultas Agama Islam Universitas Islam Riau.

Dengan menggunakan uji regresi linear sederhana ditemukan bahwa $\mathrm{p}>$ 0,05 dimana nilai signifikansi 0,05 . Adapun hasil yang diperoleh melalui SPSS 20 adalah sebagai berikut:

Tabel 6

Uji Regresi

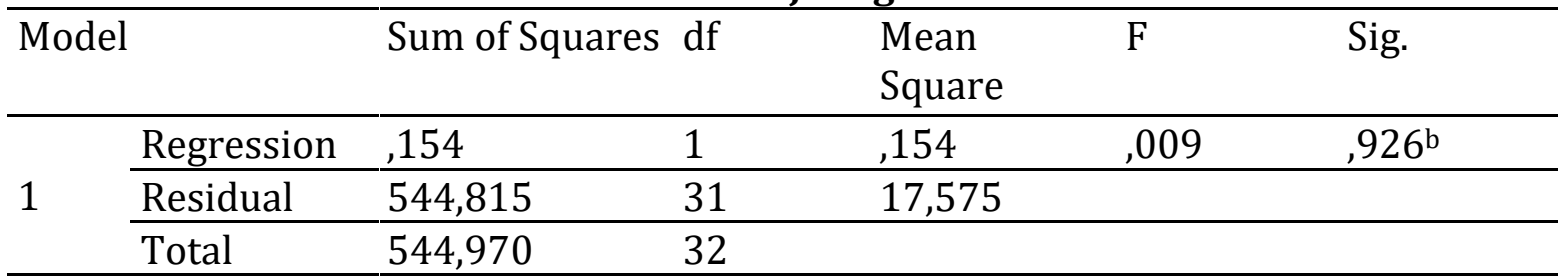

a. Dependent Variable: Penyesuaian Diri

b. Predictors: (Constant), Kecerdasan Emosional 

Berdasarkan di atas, diperoleh nilai signifikansi $0,926>0,05$, tergambar bahwa hipotesis penelitian yang menyatakan terdapat pengaruh antara kecerdasan emosional terhadap penyesuaian diri mahasiswa Thailand Fakultas Agama Islam adalah di tolak. Maka penyesuaian diri mahasiswa Thailand Fakultas Agama Islam tidak akan meningkat dengan adanya kecerdasan emosional yang baik. Oleh karena itu, kecerdasan emosional tidak terlalu penting dalam meningkatkan penyesuaian diri mahasiswa Thailand.

Dengan demikian nilai signifikansi $>0,05$ atau $(0,926>0,05)$ artinya tidak terdaapat pengaruh kecerdasan emosional terhadap penyesuaian diri mahasiswa Thailand Fakultas Agama Islam.

\section{Interpretasi Data}

Setelah data dikumpulkan, diolah dan dianalisis maka diperoleh hasil penelitian yang menjelaskan bahwa pengaruh kecerdasan emosional terhadap penyesuaian diri mahasiswa Thailand Fakultas Agama Islam adalah ditolak.

Dengan hasil penelitian, nilai signifikansi $>0,05$ atau $(0,926>0,05)$ artinya, tidak terdaapat pengaruh kecerdasan emosional terhadap penyesuaian diri mahasiswa Thailand Fakultas Agama Islam.

Namunseharusnya kecerdasan emosional sangatlah berpengaruh dalam penyesuaian diri, karena apabila seseorang memiliki kecerdasan emosional yang tinggi akan berpengaruh terhadap kesuksesan dan kebahagiaan hidup manusia. Kecerdasan emosional (EQ) dapat membantuk dan menciptakan hubungan yang lebih kuat, seperti sukses ditempat kerja maupun dalam kehidupan pribadi dalam komponen-komponennya sebagai berikut:

\section{Mengenali emosi}

Mengenal emosi diri dan kesadaran diri, yaitu mengetahui apa yang dirasakan seseorang pada suatu saat dan mengemukakannya untuk memandu pengambilan keputusan diri sendiri, memiliki tolak ukur yang realitas atas kemampuan diri dan kepercayaan diri yang kuat.

Kesadaran diri memungkinkan pikiran rasional memberikan informasi penting untuk menyingkirkan suasana hati yang tidak menyenangkan. Pada saat yang sama, kesadaran diri dapat membantu mengelola diri sendiri dan hubungan antar personal serta menyadari emosi dan pikiran sendiri, Semakin tinggi kesadaran diri, semakin pandai dalam menangani perilaku negatif diri sendiri.

\section{Mengelola Emosi}

Mengelola Emosi, yaitu menangani emosi sendiri agar berdampak positif bagi pelaksanaan tugas, peka terhadap kata hati dan sanggub menunda kenikmatan sebelum tercapainya satu tujuan, serta mampu menetralisir tekanan emosi.

Orang memiliki kecerdasan emosional adalah orang yang mampu menguasai, mengelola dan mengarahkan emosinya dengan baik. Pengendalian emosi tidak hanya berarti meredam rasa tertekan atau menahan gejolak emosi, melainkan juga bias bererti dengan sengaja menghayati suatu emosi, termasuk emosi yang tidak menyenangkan.

\section{Memotivasi Diri Sendiri}

Memotivasi diri, yaitu menggunakan hasrat yang paling dalam untuk menggerakkan dan menuntun manusia menuju sasaran, membantu mengambil inisiatif dan bertindak sangat efektif serta bertahan 
menghadapi kegagalan dan frustasi.Kunsi motivasi adalah memanfaatkan emosi, sehingga dapat mendukung kesuksesan hidup seseorang, dan sebaliknya perilaku sering kali menentukan emosinya.

Bahkan menurut Golmen motivasi dan emosi pada dasarnya memiliki kesamaan, yaitu sama menggerakkan. Motivasi menggerakkan manusia untuk meraih sasaran, emosi menjadi bahan bakar untuk motivasi, dan motivasi pada gilirannya menggerakkan perpepsi dan membentuk tindakan-tindakan.

\section{Mengenali Emosi Orang Lain}

Mengenali emosi orang lain, yaitu kemampuan untuk merasakan apa yang dirasakan orang lain, mampu memahami perpektif mereka, menumbuhka hubungan saling percaya dan menyelaraskan diri dengan orang banyak atau masyarakat.

Hal ini berarti orang memiliki kecerdasan emosional ditandai dengan kemampuan untuk memahami perasaan atau emosi orang lain. Emosi jarang diungkapkan melalui pesan nonverbal, senada suara, ekresi wajah, gerak-gerik, dan sebagainya. Kemampuan mengindra, memahami dan membaca perasaan atau emosi orang lain melalui pesan-pesan nonverbal ini merupakan inti sari dari empati.

\section{Membina Hubungan}

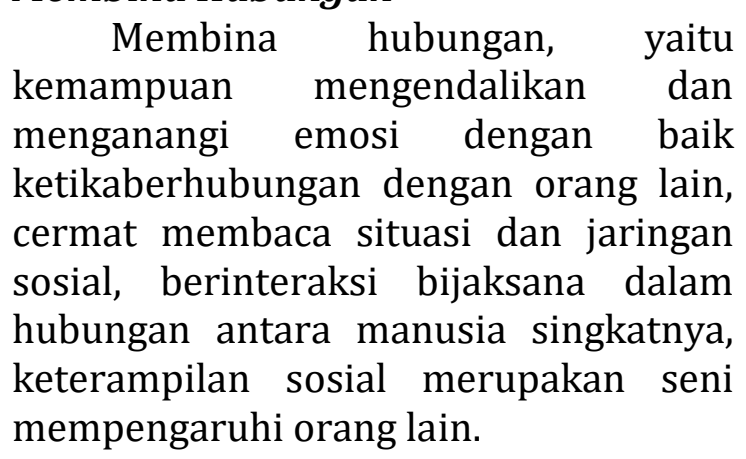

\begin{abstract}
Dengan kecerdasan emosional yang dimiliki, diharapkan dapat menyesuaikan diri dengan mudah.Kecerdasan emosional juga dapat mematangkan pola perilaku dalam menyesuaikan diri, agar mahasiswa tidak memiliki rasa rendah diri, tidak percaya diri.
\end{abstract}

\section{SIMPULAN}

Setelah dilakukan pembahasan dan penganalisaan terhadap data yang diperoleh dari jawaban responden maka dapat disimpulkan bahwa tidak terdapat pengaruh Kecerdasan Emosional Terhadap Penyesuaian Diri Mahasiswa Thailand. hal ini berdasarkan hasil pengelolaan data primer angket pada tabel ANOVA dapat diketahui bahwa nilai signifikansi 0,926>0,05 yang artinya tidak terdapat pengaruh antara Kecerdasan Emosional Terhadap Penyesuaian Diri Mahasiswa Thailand.

Setelah mengetahui hasil penelitian yang penulis lakukan, ada beberapa saran yang ingin penulis sampaikan, antara lain: (1) Bagi mahasiswa Thailand, agar dapat memahami lebih dalam tentang kecerdasan emosional dan penyesuaian diri secara teori dan praktek; dan (2) Bagi dosen, untuk dapat dijadikan landasan/dasar dalam memberikan masukan kepada mahasiswa dalam meningkatkan penyesuaian diri mahasiswa.

\section{DAFTAR RUJUKAN}

Agustian,Ginanjar. 2005.Rahasiasuksesmembangunke cerdasanemosidanspiritual. Jakarta: the ESQ way 165.

Ali, Mohammad dan Asrori, Mohammad. 2004. PsikologiRemaja. Jakarta: PT BumiAksara. 
Arikunto, Suharsimi. 2006. Prosedur Penelitian Suatu Pendekatan Praktik. Jakarta: Rineka Cipta.

Baharuddin. 2014.Psikologi Perkembangan. Yogyakarta: Arruzz Media.

Bambang,Andik. 2004. Peranan Kecerdasan Emosional Dalam Meningkatkan KualitasBelajar Pendidikan Agama Islam Siswa AMK Kosgoro I Lawang Malang. Skripsi. Malang: Universitas Islam Negeri Maulana Malik Ibrahim.

Ghufron, M.Nur dan S., RiniRisnawita. 2010. Teori-Teori Psikologi. Jogjakarta:Ar-Ruzz Media.

Jurnita. 2011. Hubungan Kecerdasan Emosional Dengan Aklhak Terpuji Siswa Madrasah Aliyah Swasta (MAS) Masmur Pekanbaru. Skripsi. Pekanbaru: Fakultas Agama IslamUnivesitas Islam Riau.

Masaong,Kodim. 2011. Kepemimpinan berbasis multiple intelegence. Jakarta: Rosda.

Mashar,Riana.

2011.

\section{Emosianakdinidanstrategi} pengembangannya. Jakarta:kencana.

Nata,Abuddin.2009.Akhlak Tasawuf. Jakarta: PT. Raja Grafindo Persada.

Nurluqman,Gatot. 1997. Urgensi Kecerdasan Emosional Sebagai Paradiqma Baru Pendidikan Anak Di Lingkungan Keluarga.
Skripsi.Malang: Universitas Islam Negeri Maulana Malik Ibrahim.

Rumini, Sri dan Sundari, Siti. 2004. PerkembanganRemaja. Jakarta: PT. Rineka Cipta.

Sugiyono. 2015. Statistika untuk Penelitian. Bandung: Alfabeta.

Sukmadinata,Nana Syaodih.2003. LandasanPsikologi Proses Pendidikan. Bandung: PT RemajaRosdakarya.

Sunarto danHartono,Agung. 2008. PerkembanganPesertaDidik . Jakarta: PT. Rineka Cipta.

Syam,Suardi. 2015. PsikologiPerkembanganPesertaDidi $k$. Yogyakarta:NUSA MEDIA.

Tohwae-aryi, Ismaael. 2009. Problematika Yang Dihadapi Mahasiswa Islam Patani Dalam Melanjudkan Studi.Skripsi. Pekanbaru: Fakultas Agama IslamUnivesitas Islam Riau.

Wahab,Rohmalina. 2015. PsikologiBelajar. Jakarta: PT Raja Grafindo Persada.

Wahyuningsih,Amelia Sawitri. 2004. Hubungan Antara Kecerdasan Emosional Dengan Prestasi Belajar Pada Siswa Kelas II SMU Lab School Jakarta Timur. Skripsi. Jakarta: Universitas Persada Indonesia Y.A.I,.

Yaumi,Muhammad danIbrahim, Nurdin. 2010. Kecerdasan Jamak. Jakarta: Jaya Pustaka. 